\title{
Sonic Hedgehog is a novel prognostic biomarker in patients with oral squamous cell carcinoma
}

\author{
Piotr CIERPIKOWSKI*, Anna LIS-NAWARA, Julia BAR \\ Department of Immunopathology and Molecular Biology, Wroclaw Medical University, Wroclaw, Poland \\ ${ }^{*}$ Correspondence: cierpikowski@gmail.com
}

Received December 4, 2020 / Accepted March 23, 2021

\begin{abstract}
Recent studies revealed that Sonic Hedgehog ( $\mathrm{SHH}$ ) signaling pathway plays an important role in initiation and tumor progression in various malignancies, however, its role in oral squamous cell carcinoma (OSCC) remains unclear. The objective of this study was to investigate the prognostic significance of SHH expression in patients with OSCC in relation to p53 protein expression and human papillomavirus (HPV) presence. SHH, p53, HPV expression was analyzed in surgical specimens from 70 patients with primary OSCC by immunohistochemistry (IHC) and correlated with clinicopathological parameters. The presence of SHH, p53, HPV was found in 51/70 (72.9\%), 32/70 (45.7\%), 11/70 (15.7\%) cases, respectively. No correlation between SHH, p53 overexpression, and HPV presence was found. SHH expression was associated with tumor stage $(\mathrm{p}=0.026)$. P53 immunoreactivity correlated with tumor grade $(\mathrm{p}=0.040)$. By Kaplan-Meier analysis, $\mathrm{SHH}$ expression was significantly associated with shorter overall survival $(\mathrm{p}=0.005)$. Multivariate cox regression analysis showed that $\mathrm{SHH}$ was an independent prognostic factor for overall survival $(\mathrm{HR}=2.93 ; 95 \% \mathrm{CI}=1.40-6.13 ; \mathrm{p}=0.004)$. Our findings revealed that the $\mathrm{SHH}$ signaling pathway contributes to the poor survival of patients with OSCC and should be considered as a new prognostic biomarker in patients with OSCC. Inhibition of the SHH pathway may be used as a new potential target in cancer therapy.
\end{abstract}

Key words: SHH, p53, HPV, oral squamous cell carcinoma, prognosis, survival

Oral carcinoma is one of the most common malignancies worldwide with highly invasive behavior and poor prognosis [1]. More than $90 \%$ of cases that are formed from tissues of the oral cavity present as oral squamous cell carcinoma (OSCC) [2]. The most known risk factor for OSCC incidence is chronic exposure to smoking [3]. However, infection of oral mucosa by the human papillomavirus (HPV) is also a proven etiologic factor, especially within younger patients [3]. Radical surgical resection in combination with radiotherapy or chemotherapy is an established treatment option for OSCC [4]. Despite recent advances in medical therapy, the survival of patients with OSCC has not improved over the last few decades $[4,5]$. The major causes of high mortality are high tumor invasion, lymph node involvement, poor response to therapy, and early local recurrence $[3,6,7]$. Growing evidence suggests that the growth of OSCC might be caused by carcinoma cells, which possess stemness features [4]. The prediction of OSCC behavior and clinical outcome using currently available conventional clinicopathological parameters is not sufficient. Therefore, it is essential to identify effective biomarkers, which predict the prognosis of patients with
OSCC and may also be a potential target for novel therapies in the future. Cancer stem-like cells (CSCs) theory provides a new direction regarding the recurrence mechanism in tumors [4]. CSCs detected in OSCC might determine biological, aggressive growth of OSCCs by self-renewal of CSCs existed in tumor tissue $[4,8]$. Self-renewal of CSCs can be maintained by several endogenous signaling pathways, such as Hedgehog, Notch, Wnt, B-cell-specific Moloney murine leukemia virus integration site 1 (Bmil), Pten, Bmp, and TGF- $\beta$, which are frequently activated in human cancers [8].

Sonic Hedgehog signaling pathway (SHH), one of the components belonging to the Hedgehog pathway $(\mathrm{HH})$, originally plays a fundamental role in proliferation, differentiation, and migration of certain stem cells during embryogenesis $[9,10]$. However, the SHH pathway plays also an important role in human carcinoma [11]. Aberrant activation of the SHH pathway was firstly observed in basal cell carcinoma, where selective inhibitors (e.g., vismodegib, sonidegib) are used successfully [12]. Recent studies reported that $\mathrm{SHH}$ overexpression is closely related to tumorigenesis, metastasis, angiogenesis, and cancer relapse $[5,8,9,13]$. 
However, the role of SHH in OSCC remains still unclear. Most of the previous studies concerning OSCC focused on other components of the HH pathway like Gli, Smo, Ptch $[6,14]$. In addition, a positive correlation between $\mathrm{SHH}$ expression and survival of patients with OSCC has not been reported $[7,10,15]$.

P53 protein (p53) is one of the well-known molecules analyzed in human cancer. P53 plays a critical role in cell cycle control, DNA damage repair, and apoptosis $[16,17]$. TP53 gene alteration leads to loss of suppressive function of p53 protein $[18,19]$. P53 overexpression was observed in various human tumors (e.g., lung, colorectal, gastric, laryngeal, esophageal, ovarian cancer) including OSCC [16]. It was reported that the $\mathrm{p} 53$ overexpression is correlated with poor prognosis, although, its association with survival in OSCC is controversial $[18,19]$. It is worthwhile to underline that $\mathrm{p} 53$ protein expres-

Table 1. Clinicopathological characteristics of patients with oral squamous cell carcinoma.

\begin{tabular}{|c|c|}
\hline Parameter & $\mathbf{N}(\%)$ \\
\hline \multicolumn{2}{|l|}{ Gender } \\
\hline Female & $23(32.9)$ \\
\hline Male & $47(67.1)$ \\
\hline \multicolumn{2}{|l|}{ Tumor grade } \\
\hline G1 & $26(37.1)$ \\
\hline G2 & $36(51.4)$ \\
\hline G3 & $8(11.4)$ \\
\hline \multicolumn{2}{|l|}{ Tumor location } \\
\hline Tongue & $30(42.9)$ \\
\hline Floor of the mouth & $18(25.7)$ \\
\hline Other (cheek, gingiva, palate) & $22(31.4)$ \\
\hline \multicolumn{2}{|l|}{ Tumor stage } \\
\hline pT1 & $15(21.4)$ \\
\hline pT2 & $15(21.4)$ \\
\hline pT3 & $27(38.6)$ \\
\hline pT4 & $13(18.6)$ \\
\hline \multicolumn{2}{|l|}{ Lymph node metastasis } \\
\hline Yes & $26(36.4)$ \\
\hline No & $44(63.6)$ \\
\hline \multicolumn{2}{|l|}{ Clinical stage } \\
\hline $\mathrm{I} / \mathrm{II}$ & $24(34.3)$ \\
\hline III/IV & $46(65.7)$ \\
\hline \multicolumn{2}{|l|}{ Survival status } \\
\hline Alive & $22(31.4)$ \\
\hline Dead & $48(68.6)$ \\
\hline \multicolumn{2}{|l|}{ SHH expression } \\
\hline Positive & $51(72.9)$ \\
\hline Negative & $19(27.1)$ \\
\hline \multicolumn{2}{|l|}{ p53 expression } \\
\hline Positive & $32(45.7)$ \\
\hline Negative & $38(54.3)$ \\
\hline \multicolumn{2}{|l|}{ HPV expression } \\
\hline Positive & $11(15.7)$ \\
\hline Negative & $59(84.3)$ \\
\hline
\end{tabular}

Abbreviations: SHH-Sonic Hedgehog; HPV-human papillomavirus sion plays a crucial role in mesenchymal stem cells' differentiation [20]. However, there are data that observed nuclear accumulation of p53 in carcinoma stem cells [20]. Double staining in ovarian carcinoma showed that p53 overexpression was associated with CD133 and Notch1 expression [21, 22]. Cases with co-expression of p53 and Notch1 or CD133 revealed resistance to cisplatin-based therapy by in vitro study $[21,22]$. These results suggest that $\mathrm{p} 53$ protein in correlation with stem cells' biomarkers might influence the biological behavior of this cell subpopulation $[21,22]$.

Human papillomavirus (HPV) is considered a risk factor of various human cancers including OSCC [3]. HPV shows tropism to epithelial cells, where integrates with the host genome and leads to $\mathrm{p} 53$ inactivation and cell proliferation [3, 21,23 The prevalence of HPV infection in OSCC is controversial and according to the previous reports varies from $0 \%$ to $82.8 \%[23,24]$. Recent data showed that HPV infection is identified as a favorable prognostic factor in head and neck cancers (HNSCC), especially throat and tonsils cancers [25]. However, it was not proven that HPV-positive OSCC is associated with a better prognosis [24]. Only individual data analyzed the correlation between the $\mathrm{HH}$ pathway and HPV infection in HNSCC [26]. The authors found that some of the $\mathrm{HH}$ pathway proteins, such as Gli1, Gli2 may act as prognostic factors in patients with HPV-negative HNSCC [26]. Little is known about the relationship between the $\mathrm{SHH}$ signaling pathway activation and $\mathrm{p} 53$ expression, HPV infection, and prognosis of patients with OSCC.

The aim of our study was to investigate the expression and prognostic value of $\mathrm{SHH}$ as a potential biomarker in patients with OSCC with respect to the other known risk factors of oral cancer like p53 expression and HPV infection.

\section{Patients and methods}

Patients and tissue samples. 70 excisional surgical specimens were obtained at the Department of Pathomorphology and Oncological Cytology of Wroclaw Medical University from patients diagnosed with OSCC between 2011-2015 (Head of Department: prof. Michal Jelen). All patients included in this study were treated by surgery with primary OSCC only from the following sites: tongue, floor of the mouth, cheek, gingiva, and palate. Patients with other localization of the tumor, non-OSCC histopathology, or treated before surgery were excluded. Specimens were histopathologically graded and tumors were categorized as well (G1), moderately (G2), or poorly differentiated (G3) according to the current WHO classification [27]. Pathological tumor stage (pT), lymph node metastasis status, and clinical staging were established according to the 2009 American Joint Committee on Cancer (AJCC) $7^{\text {th }}$ edition staging criteria [28]. Specimens were divided into 4 groups of pT stage (depending on tumor size), 2 groups of lymph node metastasis status (absent or present), and 2 groups of the clinical stage (low stage: I/II, high stage: III/IV). Patient 
age ranged from 35 to 82 years (mean: 62.8 years). The mean follow-up time of overall survival was 49.1 months (25.559.6) for alive patients and 14.3 months (1-43) for deceased patients. Table 1 shows the complete clinicopathological features of patients. The present study was accepted by the Ethics Committee of Wroclaw Medical University with a protocol number KB-230/2016.

Immunohistochemistry (IHC). Immunohistochemical staining of analyzed proteins was performed on paraffinembedded OSCC tissues from the selected blocks using the Universal Dako REAL EnVision Detection System, Peroxidase/DAB+, Rabbit/Mouse (Dako, Copenhagen, Denmark) and specific antibodies: anti-SHH (ab53281; clone EP1190Y; Abcam, Cambridge, UK), anti-p53 (NCL-p53-DO7; clone DO-7; Novocastra, Newcastle, UK), and anti-HPV (ab75574; clone K1H8; Abcam, Cambridge, UK) that recognizes highrisk HPV subtypes: 6, 11, 16, 18, 31, 33, 42, 51, 52, 56, 58. All paraffin-embedded OSCC blocks were cut into $4 \mu \mathrm{m}$ slides, deparaffinized, and antigen-retrieved in citrate buffer ( $\mathrm{pH}$ 6.0) by microwave heating at $800 \mathrm{~W}$ for $2 \times 5$ minutes for each antibody. After microwaving, the slides were cooled for 30 minutes. Endogenous peroxidase and nonspecific binding of used antibodies were blocked with Dako REAL Peroxidase Blocking Solution (Dako, Copenhagen, Denmark). Tissue sections were incubated with primary antibodies (anti-SHH, dilution 1:200; anti-p53, dilution 1:50, anti-HPV, prediluted) overnight at $4{ }^{\circ} \mathrm{C}$. Afterward, tissue slides were washed with $0.1 \mathrm{M}$ Tris-buffer, $\mathrm{pH} 7.4$ (TBS) and incubated (30 min at room temperature) with Dako REAL EnVision/HRP, Rabbit/ Mouse (Dako, Copenhagen, Denmark). After washing with TBS, the slides were incubated with DAB (3,3'-diaminobenzidine) (Dako, Copenhagen, Denmark) as a chromogen (8 min at room temperature) and then counterstained with hematoxylin. The internal positive controls were performed according to the manufacturer's instructions. Negative controls were prepared using TBS instead of primary antibodies.

Interpretation of IHC reaction. The intensity of $\mathrm{SHH}$, p53, HPV immunostaining and the percentage of tumor tissue with positive reaction were evaluated semi-quantitatively in the tissue slides by two independent investigators with the usage of a double-headed light microscope Olympus BX-51 (Olympus, Tokyo, Japan). SHH expression was assessed by determining membranous immunostaining based on the intensity of immunostaining and the percentage of positive tumor tissue area. Immunoreactivity of p53 and HPV was evaluated by counting 1000 tumor cells in 10 randomly selected high-power fields in relation to the total number of tumor cells. A positive reaction was judged when immunostaining of SHH, p53, HPV was present in $10 \%$ or more of tumor cells. The intensity of the reaction was scored as negative, weak, moderate, strong.

Statistical analysis. Associations between $\mathrm{SHH}, \mathrm{p} 53$, HPV expression and clinicopathological data were statistically evaluated by $\chi^{2}$ test, Mann-Whitney, and Kruskal-Wallis tests. Correlations between proteins were performed using
Spearman's test. For overall survival analysis, Kaplan-Meier and log-rank tests were used. Overall survival (OS) in months was calculated from the day of surgery to the last follow-up examination or death. Cox-regression analyses were calculated to identify prognostic factors for OS. For the purpose of statistical analyses, $\mathrm{SHH}, \mathrm{p} 53$, HPV expression was divided into two groups: negative - less than $10 \%$ positive tumor tissue area and positive $-10 \%$ or more positive tumor tissue area. In all cases statistically significant $\mathrm{p}$-values were $\mathrm{p}<0.05$. Statistical analysis was performed by using STATISTICA v13.0 (Statsoft, Krakow, Poland).

\section{Results}

SHH, p53, and HPV expression in oral squamous cell carcinoma. SHH expression was observed in 51/70 (72.9\%) cases and ranged from 10-80\% (median: 40\%) of tumor tissue (Figure 1A). No positive reaction was observed in

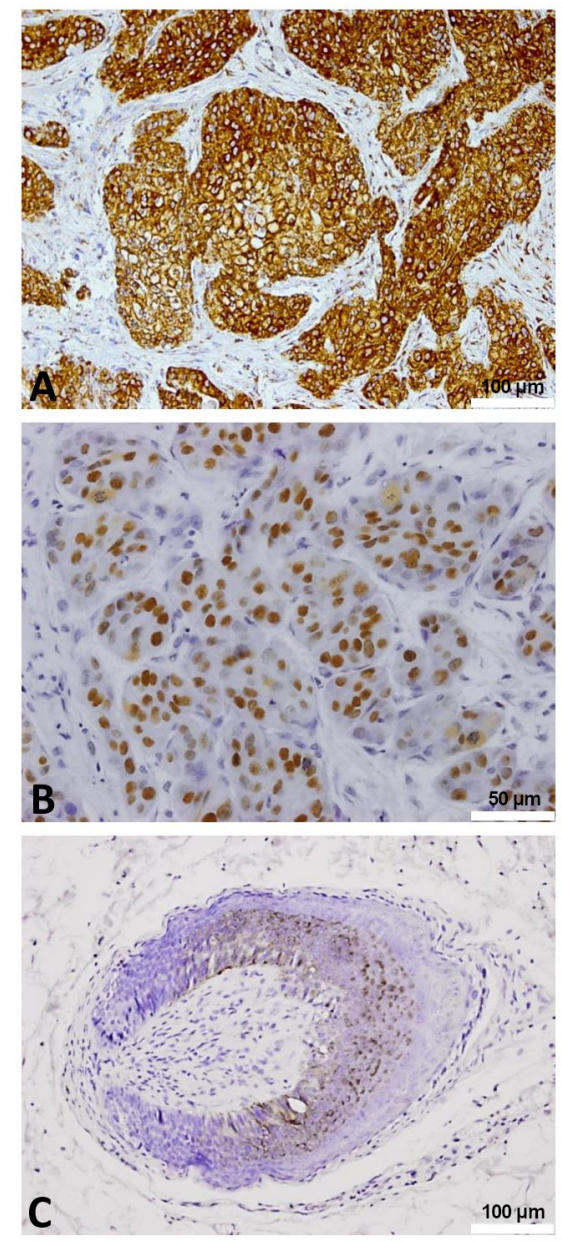

Figure 1. Immunohistochemical staining of $\mathrm{SHH}, \mathrm{p} 53$, and HPV in OSCC tissues (EnVision technique). A) Intensive, membranous immunostaining of $\mathrm{SHH}$ in a high percentage of OSCC tissue. Scale bar, $100 \mu \mathrm{m}$. B) Nuclear accumulation of p53 protein in OSCC cells. Scale bar, $50 \mu \mathrm{m}$. C) HPV presence in oral cancer cells. Scale bar, $100 \mu \mathrm{m}$. 
Table 2. Association between clinicopathological parameters and protein expression in patients with oral squamous cell carcinoma.

\begin{tabular}{|c|c|c|c|c|c|c|c|c|c|}
\hline \multirow{2}{*}{ Parameter } & \multicolumn{3}{|c|}{ SHH, n (\%) } & \multicolumn{3}{|c|}{ p53, n (\%) } & \multicolumn{3}{|c|}{ HPV, n (\%) } \\
\hline & negative & positive & p-value & negative & positive & p-value & negative & positive & p-value \\
\hline \multicolumn{10}{|l|}{ Gender } \\
\hline Female & $9(39.1)$ & $14(60.9)$ & \multirow{2}{*}{0.115} & $15(65.2)$ & $8(34.8)$ & \multirow{2}{*}{0.199} & $20(87.0)$ & $3(13.0)$ & \multirow{2}{*}{0.668} \\
\hline Male & $10(21.3)$ & $37(78.7)$ & & $23(48.9)$ & $24(51.1)$ & & $39(83.0)$ & $8(17.0)$ & \\
\hline \multicolumn{10}{|l|}{ Tumor grade } \\
\hline G1 & $6(23.1)$ & $20(76.9)$ & \multirow{3}{*}{0.719} & $16(61.5)$ & $10(38.5)$ & \multirow{3}{*}{0.040} & $24(92.3)$ & $2(7.7)$ & \multirow{3}{*}{0.290} \\
\hline G2 & $10(27.8)$ & $26(72.2)$ & & $21(58.3)$ & $15(41.7)$ & & $28(77.8)$ & $8(22.2)$ & \\
\hline G3 & $3(37.5)$ & $5(62.5)$ & & $1(12.5)$ & $7(87.5)$ & & $7(87.5)$ & $1(12.5)$ & \\
\hline \multicolumn{10}{|l|}{ Tumor site } \\
\hline Tongue & $10(33.3)$ & $20(66.7)$ & \multirow{3}{*}{0.454} & $13(43.3)$ & $17(56.7)$ & \multirow{3}{*}{0.251} & $26(86.7)$ & $4(13.3)$ & \multirow{3}{*}{0.679} \\
\hline Flour of the mouth & $3(16.7)$ & $15(83.3)$ & & $12(66.7)$ & $6(33.3)$ & & $14(77.8)$ & $4(22.2)$ & \\
\hline Other (cheek, gingiva, palate) & $6(27.3)$ & $16(72.7)$ & & $13(59.1)$ & $9(40.9)$ & & $19(86.4)$ & $3(13.6)$ & \\
\hline \multicolumn{10}{|l|}{ Tumor stage } \\
\hline pT1 & $8(53.3)$ & 7 (46.7) & \multirow{4}{*}{0.026} & $7(46.7)$ & $8(53.3)$ & \multirow{4}{*}{0.275} & $14(93.3)$ & $1(6.7)$ & \multirow{4}{*}{0.355} \\
\hline pT2 & $2(13.3)$ & $13(86.7)$ & & $11(73.3)$ & $4(26.7)$ & & $14(93.3)$ & $1(6.7)$ & \\
\hline pT3 & $8(29.6)$ & $19(70.4)$ & & $15(55.6)$ & $12(44.4)$ & & $21(77.8)$ & $6(22.2)$ & \\
\hline pT4 & $1(7.7)$ & $12(92.3)$ & & $5(38.5)$ & $8(61.5)$ & & $10(76.9)$ & $3(23.1)$ & \\
\hline \multicolumn{10}{|l|}{ Lymph node metastasis } \\
\hline Yes & $4(15.4)$ & $22(84.6)$ & \multirow{2}{*}{0.089} & $14(53.8)$ & $12(46.2)$ & \multirow{2}{*}{0.955} & $20(76.9)$ & $6(23.1)$ & \multirow{2}{*}{0.193} \\
\hline No & $15(34.1)$ & $29(65.9)$ & & $24(54.5)$ & $20(45.5)$ & & 39 (88.6) & $5(11.4)$ & \\
\hline \multicolumn{10}{|l|}{ Clinical stage } \\
\hline $\mathrm{I} / \mathrm{II}$ & $8(33.3)$ & $16(66.7)$ & \multirow{2}{*}{0.400} & $15(62.5)$ & $9(37.5)$ & \multirow{2}{*}{0.319} & $22(91.7)$ & $2(8.3)$ & \multirow[t]{2}{*}{0.220} \\
\hline III/IV & $11(23.9)$ & $35(76.1)$ & & $23(50.0)$ & $23(50.0)$ & & $37(80.4)$ & $9(19.6)$ & \\
\hline
\end{tabular}

Abbreviations: SHH-Sonic Hedgehog; HPV-human papillomavirus. Notes: $\chi^{2}$ test; bold values indicate statistical significance (p<0.05)

Table 3. Spearman's rank correlation between expression levels of $\mathrm{SHH}$ p53, HPV in oral squamous cell carcinomas.

\begin{tabular}{|c|c|c|c|c|c|c|}
\hline & \multicolumn{2}{|c|}{ SHH } & \multicolumn{2}{|c|}{ p53 } & \multicolumn{2}{|c|}{ HPV } \\
\hline & $\mathbf{r}$ & p-value & $\mathbf{r}$ & p-value & $\mathbf{r}$ & p-value \\
\hline SHH & & & -0.159 & 0.187 & 0.118 & 0.333 \\
\hline p53 & -0.159 & 0.187 & & & 0.118 & 0.330 \\
\hline HPV & 0.118 & 0.333 & 0.118 & 0.330 & & \\
\hline
\end{tabular}

Abbreviations: SHH-Sonic Hedgehog; HPV-human papillomavirus

stromal cells. Taking into account the localization of the malignant lesion site, the $\mathrm{SHH}$ expression was observed in $66.7 \%(20 / 30)$ tongue, $83.3 \%$ (15/18) floor of the mouth, and $72.7 \%(16 / 22)$ cheek, gingiva, palate carcinomas.

The p53 overexpression was found in 32/70 (45.7\%) samples. P53 was localized in cell nuclei. Immunoreactivity of p53 was noted from 10-90\% (median: 30\%) of tumor tissue (Figure 1B). Stromal cells did not reveal p53 immunopositivity. P53 expression was noted in 56.7\% (17/30) tongue, $33.3 \%$ (6/18) floor of the mouth, and 40.9\% (9/22) cheek, gingiva, palate carcinomas.

HPV infection was detected in $11 / 70$ (15.7\%) cases. The presence of HPV was mainly restricted to the low area (10-20\%) of tumor tissue (median: 10\%) and HPV-positive cells were distributed throughout tumor tissue (Figure 1C). HPV expression was found in 13.3\% (4/30) tongue, $22.2 \%$ (4/18) floor of the mouth, and 13.6\% (3/22) cheek, gingiva, palate carcinomas.
Correlations between SHH, p53, HPV expression, and clinicopathological parameters. The presence of $\mathrm{SHH}$ was significantly associated with a higher tumor stage $(\mathrm{p}=0.026)$. $\mathrm{SHH}$ overexpression was dominant among pT4 tumors (92.3\%). High expression of $\mathrm{SHH}$ was correlated with the presence of lymph node metastasis but did not reach statistical significance $(\mathrm{p}=0.089)$. The presence of $\mathrm{p} 53$ correlated with tumor grade $(\mathrm{p}=0.040)$ and increased $\mathrm{p} 53$ expression was found more frequently in poorly differentiated carcinomas (G3) (Table 2). The Spearman's rank test did not reveal any statistically significant correlations between studied proteins (Table 3 ).

Survival analysis. The analysis of overall survival was performed on all cases included in this study. The 3-year overall survival rate was $37.1 \%$ (26/70). Kaplan-Meier survival curves were plotted according to clinicopathological parameters, SHH, p53, and HPV expression. Kaplan-Meier analysis with log-rank test showed that tumor grade, tumor stage, lymph node metastasis, and clinical stage were associated with worse OS $(\mathrm{p}=0.047 ; \mathrm{p}<0.001 ; \mathrm{p}=0.003 ; \mathrm{p}<0.001$, respectively). It was found that the $\mathrm{SHH}$ expression significantly correlated with shorter OS patients with OSCC $(p=0.005)$. We observed also a correlation between HPV status and worse OS but this association did not reach statistical significance $(p=0.055)$. There was no correlation observed between survival time of OSCC patients and gender, p53 expression (Figure 2). 
In univariate analysis, tumor stage, lymph node metastasis, clinical stage and SHH, HPV expression correlated significantly with worse OS $(\mathrm{p}<0.001 ; \mathrm{p}=0.002 ; \mathrm{p}<0.001$; $\mathrm{p}=0.012 ; \mathrm{p}=0.028$, respectively). There was no association observed between OS and gender, tumor grade, p53 expression (Table 4).

In multivariate analysis, tumor grade, tumor stage, and $\mathrm{SHH}$ expression was noted as significant independent prognostic factor for survival of OSCC patients $(\mathrm{p}=0.008$; $\mathrm{p}<0.001 ; \mathrm{p}=0.004$; respectively) (Table 4 ).

\section{Discussion}

In the present study, we estimated SHH, p53, HPV expression, and the association between these proteins in OSCC tissue in order to establish their impact on tumor progression as well as to define its prognostic significance in patients with OSCC. The majority of published data claims that the uncontrolled upregulation of the Sonic hedgehog signaling pathway results in carcinogenesis and tumor growth $[9$, 13, 26]. Upregulation of SHH was described in some solid
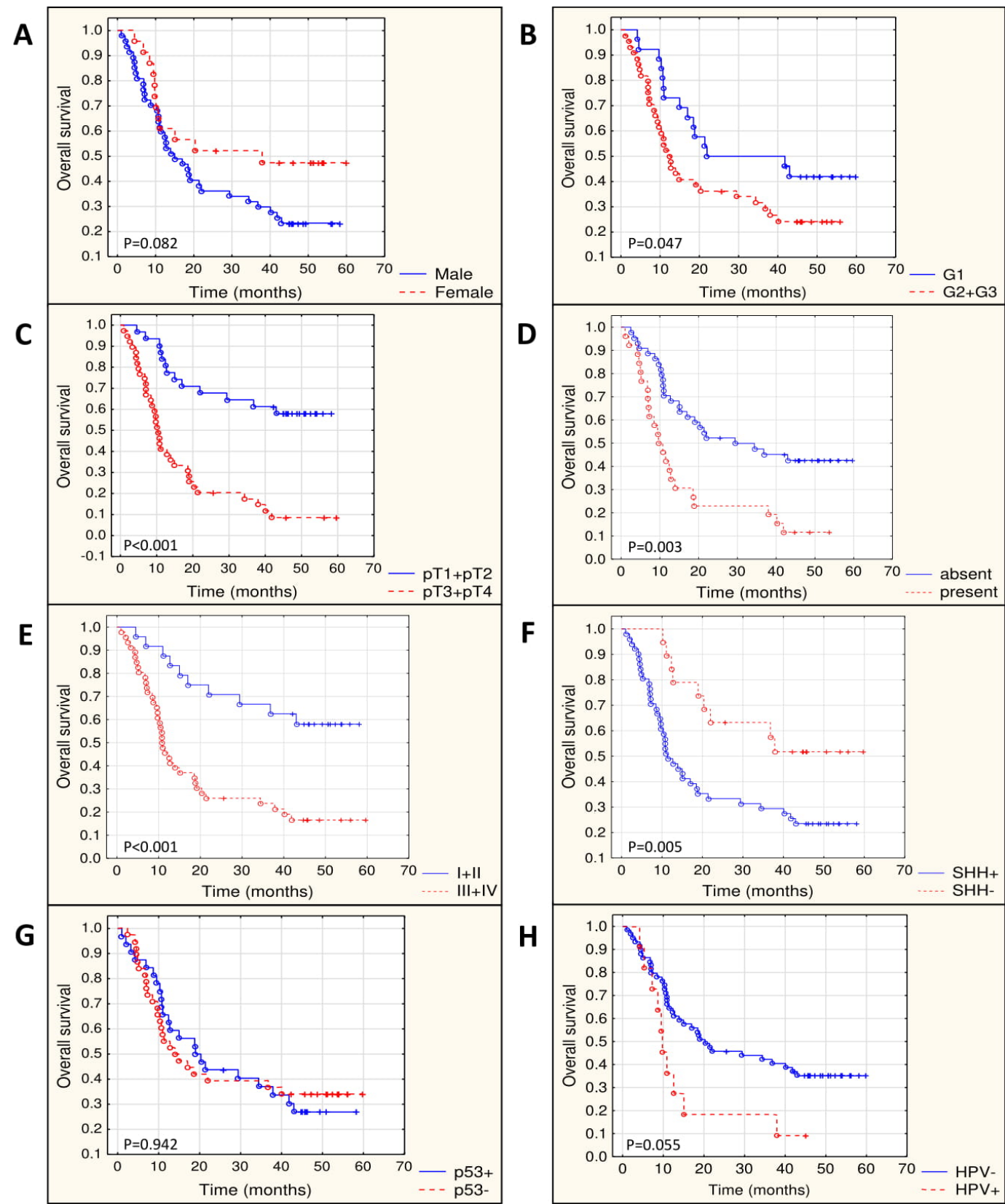

Figure 2. Kaplan-Meier analysis of overall survival curves for gender (A), tumor grade (B), tumor stage (C), lymph node metastasis (D), clinical stage (E), SHH expression (F), p53 expression (G), HPV presence (H) in OSCC patients (p-values of the log-rank test). 
Table 4. Univariate and multivariate Cox regression analysis of overall survival in patients with oral squamous carcinoma.

\begin{tabular}{|c|c|c|c|c|}
\hline \multirow{2}{*}{ Parameter } & \multicolumn{2}{|c|}{ Univariate } & \multicolumn{2}{|c|}{ Multivariate } \\
\hline & HR (95\% CI) & p-value & HR $(95 \% \mathrm{CI})$ & p-value \\
\hline $\begin{array}{l}\text { Gender } \\
\text { Female/Male }\end{array}$ & $0.57(0.30-1.10)$ & 0.096 & & \\
\hline $\begin{array}{l}\text { Tumor grade } \\
\text { G1/G2+G3 }\end{array}$ & $1.81(0.98-3.33)$ & 0.058 & $2.32(1.25-4.34)$ & 0.008 \\
\hline $\begin{array}{l}\text { Tumor stage } \\
\text { pT1+pT2/pT3+pT4 }\end{array}$ & $4.35(2.27-8.36)$ & $<0.001$ & $4.87(2.49-9.52)$ & $<0.001$ \\
\hline $\begin{array}{l}\text { Lymph node metastasis } \\
\text { Yes/No }\end{array}$ & $2.53(1.42-4.48)$ & 0.002 & & \\
\hline $\begin{array}{l}\text { Clinical stage } \\
\text { I+II/III+IV }\end{array}$ & $1.88(1.32-2.68)$ & $<0.001$ & & \\
\hline $\begin{array}{l}\text { SHH expression } \\
\text { Positive/Negative }\end{array}$ & $2.53(1.22-5.23)$ & 0.012 & $2.93(1.40-6.13)$ & 0.004 \\
\hline $\begin{array}{l}\text { p53 expression } \\
\text { Positive/Negative }\end{array}$ & $1.02(0.58-1.80)$ & 0.942 & & \\
\hline $\begin{array}{l}\text { HPV expression } \\
\text { Positive/Negative } \\
\end{array}$ & $2.21(1.09-4.49)$ & 0.028 & & \\
\hline
\end{tabular}

Abbreviations: SHH-Sonic Hedgehog; HPV-human papillomavirus; HR-hazard ratio; CI-confidence interval. Note: bold values indicate statistical significance

tumors (e.g., breast, esophageal, lung cancer) suggesting that $\mathrm{SHH}$ may be responsible for the highly invasive biological behavior of tumor but still a little is known about its role in OSCC $[29,30,31]$. In our data, SHH expression was observed in $72.9 \%$ of cases, which is consistent with previous studies $[7,10,15]$. There are data indicating that the $\mathrm{SHH}$ overexpression in OSCC is associated with tumor development to more advanced stages $[6,7,15]$. The association between $\mathrm{SHH}$ expression and higher tumor stage was observed also in the present study. The larger size of the tumor is mainly connected with more advanced cancer development. High $\mathrm{SHH}$ expression in the advanced tumor stage suggests that the SHH overexpression might promote tumor growth and induce cancer invasion [9]. In relation to the previous reports $[7,32]$, which revealed a significant positive correlation between $\mathrm{SHH}$ overexpression and lymphatic metastasis of patients with OSCC, our study showed a slight trend toward higher SHH expression in OSCC with lymph node metastasis. Similarly to Yap et al. [13], who pointed the clinical benefit from $\mathrm{SHH}$ overexpression in patients with squamous cell carcinoma of the vulva (VSCC), we might suggest that high $\mathrm{SHH}$ expression in OSCC tissue can be used as a biomarker to stratify patients of the risk of lymph node metastasis. Revealed associations between $\mathrm{SHH}$ and tumor stage and lymph node metastasis indicate that $\mathrm{SHH}$ is involved in tumor progression that was further confirmed in the survival analysis (Kaplan-Meier and Cox regression analyses).

The prognostic significance of $\mathrm{SHH}$ expression was observed in breast, esophageal, gastric, and lung cancers, suggesting that the $\mathrm{SHH}$ protein could be a valuable biomarker determining the clinical outcome of patients with OSCC [29-31, 33]. However, there is still no data confirming the association between a high SHH expression and a shorter survival time of patients with OSCC. With regard to the survival time, our study revealed that the OSCC patients with a high $\mathrm{SHH}$ expression had worse OS than the patients without SHH expression, by Kaplan-Meier analysis. Also, the multivariate analysis demonstrated that the $\mathrm{SHH}$ protein was an independent prognostic biomarker for a poor prognosis in patients with OSCC. A similar observation was reported by Lim et al. [31], who found a correlation between the $\mathrm{SHH}$ expression and a poor prognosis of the patients with extensive stage small cell lung cancer.

P53 overexpression found in $45.7 \%$ of OSCC in our study might be comparable with a study conducted by Tojyo et al. [17], who found the p53 overexpression in $63.2 \%$ of OSCC. However, there are reports that showed p53 overexpression in $34.0 \%$ HNSCC and only $16.7 \%$ OSCC $[14,34]$. The association between p53 overexpression and tumor grade found in the present paper was observed by other authors in HNSCC, but not in OSCC $[14,17,34]$. We might suggest that the $\mathrm{p} 53$ overexpression observed in poorly differentiated OSCC enhanced the aggressiveness of this subset of tumors and increase their metastasis [17-19, 35, 36]. The lack of correlation between p53 overexpression and overall survival time of patients with OSCC was observed by other authors [12]. Likewise, in HNSCC $[14,34]$, our results did not reveal the prognostic significance of p53 in OSCC.

HPV infection was found in a wide range $(0-82.8 \%)$ of the patients with OSCC $[23,24]$. The number of HPV-positive OSCC (15.7\%) observed in the present study is in an agreement with the previous data $[23,24]$. The trend of a slight correlation between HPV presence and worse OS revealed in this paper is comparable to other data, which suggested HPV infection might generate the aggressive malignancy features of OSCC [37]. Similar observations were reported by Lee et al. [38] and Duray et al. [39], who found that HPV-positive OSCC was associated with a poor prognosis and shorter survival. No correlation between HPV status and other clinicopathological parameters of OSCC observed in the present study is consistent with other studies [3].

The novel aspect of our study was to investigate whether the OSCC cells expressing $\mathrm{SHH}$ have been positive for $\mathrm{p} 53$ immunostaining and HPV infection. A lack of correlation between p53 expression, HPV status, and SHH expression in this study suggests that these proteins are not essential for the SHH signaling pathways activation. However, there are data that found an association between the $\mathrm{HH}$ pathway and p53 expression as well as between HPV presence and HH upregulation $[20,26]$. It was found that some of the $\mathrm{HH}$ signaling pathway proteins such as Gli-1 and Gli-2 showed prognostic significance in patients with HPV-negative HNSCC and low Gli protein expression in HPV-negative HNSCC patients define the high-risk patients with worse overall survival and disease-free survival [26]. SHH expression in VSCC did not show an association with HPV status [13]. The relationships between SHH and p53 in tumor cells remain still unclear [14, 
20]. Similarly, to Richtig et al. [14], we do not find any correlation between SHH and p53 protein expression in OSCC. However, other reports indicated that the mutant form of $\mathrm{p} 53$ protein increased the Hedgehog signaling pathway [20].

In conclusion, our findings reveal that the Sonic Hedgehog signaling pathway is activated in OSCC and contributes to the poor survival of patients with OSCC. Increased expression of $\mathrm{SHH}$ is an independent negative prognostic biomarker in OSCC. Additionally, high SHH expression in OSCC with lymph node metastasis indicates that the $\mathrm{SHH}$ expression might be considered as a factor determining the risk of carcinoma cells to progression and metastasis. Further studies are needed to investigate the possibility of the SHH signaling pathway as a new potential target for oral cancer therapy.

Acknowledgments: The authors would like to express special thanks to Prof. Michal Jelen for sharing specimens used during this study and his pathological assistance. The survey was supported by Wroclaw Medical University (grant no. STM.B132.17.0007).

\section{References}

[1] BRAY F, FERLAY J, SOERJOMATARAM I, SIEGEL RL, TORRE LA et al. Global cancer statistics 2018: GLOBOCAN estimates of incidence and mortality worldwide for 36 cancers in 185 countries. CA Cancer J Clin 2018; 68: 394-424. https://doi.org/10.3322/caac.21492

[2] GONZALEZ AC, FERREIRA M, ARIEL T, REIS SR, ANDRADE $Z$ et al. Immunohistochemical evaluation of hedgehog signalling in epithelial/mesenchymal interactions in squamous cell carcinoma transformation: a pilot study. J Oral Pathol Med 2016; 45: 173-179. https://doi.org/10.1111/ jop. 12346

[3] JIANG S, DONG Y. Human papillomavirus and oral squamous cell carcinoma: A review of HPV-positive oral squamous cell carcinoma and possible strategies for future. Curr Probl Cancer 2017; 41: 323-327. https://doi.org/10.1016/j. currproblcancer.2017.02.006

[4] SHIN KH, KIM RH. An Updated Review of Oral Cancer Stem Cells and Their Stemness Regulation. Crit Rev On$\operatorname{cog} 2018$; 23: 189-200. https://doi.org/10.1615/CritRevOncog.2018027501

[5] KURODA H, KURI N, SHIMO T, MATSUMO K, MASUI M et al. Oral Squamous Cell Carcinoma-derived Sonic Hedgehog Promotes Angiogenesis. Anticancer Res 2017; 37: 67316737. https://doi.org/10.21873/anticanres.12132

[6] CHEN G, YAN M, LI RR, CHEN WT. Sonic Hedgehog Signalling Activation Contributes to ALCAM Over-Expression and Poor Clinical Outcome in Patients with Oral Squamous Cell Carcinoma. Chin J Dent Res 2018; 21: 31-40. https:// doi.org/10.3290/j.cjdr.a39916

[7] FAN HX, WANG S, ZHAO H, LIU N, CHEN D et al. Sonic hedgehog signaling may promote invasion and metastasis of oral squamous cell carcinoma by activating MMP-9 and E-cadherin expression. Med Oncol 2014; 31: 41. https://doi. org/10.1007/s12032-014-0041-5
[8] MADHURA MG, KANSAL L, KUMAR BV. Cancer stem cell markers in oral squamous cell carcinoma - Revisited. J Med Radiol Path Surg 2019; 6: 1-3. https://doi.org/10.15713/ ins.jmrps. 152

[9] TAKABATAKE K, SHIMO T, MURAKAMI J, ANQI C, KAWAI $\mathrm{H}$ et al. The role of sonic hedgehog signaling in the tumor microenvironment of oral squamous cell carcinoma. Int J Mol Sci 2019; 20: 5779. https://doi.org/10.3390/ ijms20225779

[10] WANG Y, CHANG C, LIN C, CHANG S, CHU P et al. Expression of hedgehog signaling molecules as a prognostic indicator of oral squamous cell carcinoma. Head Neck 2012; 34: 1556-1561. https://doi.org/10.1002/hed.21958

[11] BANIEBRAHIMI G, MIR F, KHANMOHAMMADI R. Cancer stem cells and oral cancer: insights into molecular mechanisms and therapeutic approaches. Cancer Cell Int 2020; 20: 113. https://doi.org/10.1186/s12935-020-01192-0

[12] FAROOQI AA, SHU C, HUANG H, WANG H, CHANG Y et al. Trail, Wnt, sonic hedgehog, TGF $\beta$, and miRNA signalings are potential targets for oral cancer therapy. Int J Mol Sci 2017; 18: 1523. https://doi.org/10.3390/ijms18071523

[13] YAP J, FOX R, NARSIA N, PINHEIRO-MAIA S, POUNDS $\mathrm{R}$ et al. Under expression of the Sonic Hedgehog receptor, Patched1 (PTCH1), is associated with an increased risk of local recurrence in squamous cell carcinoma of the vulva arising on a background of Lichen Sclerosus. PLoS ONE 2018; 13: e0206553. https://doi.org/10.1371/journal.pone.0206553

[14] RICHTIG G, AIGELSREITER AM, ASSLABER M, WEILAND T, PICHLER $M$ et al. Hedgehog pathway proteins SMO and GLI expression as prognostic markers in head and neck squamous cell carcinoma. Histopathology 2019; 75: 118-127. https://doi.org/10.1111/his.13860

[15] SRINATH A, IYENGAR A, MYSOREKAR V. Sonic hedgehog in oral squamous cell carcinoma: An immunohistochemical study. J Oral Maxillofac Path 2016; 20: 377-383. https://doi.org/10.4103/0973-029X.190906

[16] INOUE K, KURABAYASHI A, SHUIN T, OHTSUKI Y, FURIHATA M. Overexpression of p53 protein in human tumors. Med Mol Morphol 2012; 45: 115-123. https://doi. org/10.1007/s00795-012-0575-6

[17] TOJYO I, SHINTANI Y, NAKANISHI T, OKAMOTO K, HIRAISHI Y et al. PD-L1 expression correlated with p53 expression in oral squamous cell carcinoma. Maxillofac Plast Reconstr Surg 2019; 41: 56. https://doi.org/10.1186/s40902019-0239-8

[18] LEE H, KANG Y, LEE J, BYUN J, KIM U et al. Positive expression of NANOG, mutant p53, and CD44 is directly associated with clinicopathological features and poor prognosis of oral squamous cell carcinoma. BMC Oral Health 2015; 15: 153. https://doi.org/10.1186/s12903-015-0120-9

[19] CUTILLI T, LEOCATA P, DOLO V, ALTOBELLI E. p53 as a prognostic marker associated with the risk of mortality for oral squamous cell carcinoma. Oncol Lett 2016; 12: 10461050. https://doi.org/10.3892/ol.2016.4742

[20] OLIVOUS DJ, MAYO LD. Emerging non-canonical function and regulation by p53: p53 and stemness. Int J Mol Sci 2016; 17: 1982. https://doi.org/10.3390/ijms17121982 
[21] GUPTA SM, MANIA-PRAMANIK J. Molecular mechanizms in progression of HPV-associated cervical carcinogenesis. J Biomed Sci 2019; 26: 28. https://doi.org/10.1186/ s12929-019-0520-2

[22] BAR J, GRELEWSKI P, DESZCZ I, NOGA L, HIRNLE L et al. Association between $\mathrm{p} 53$ protein phosphorylated at serine 20 expression and ovarian carcinoma stem cells phenotype: correlation with clinicopathological parameters of ovarian cancer. Neoplasma 2019; 66: 801-809. https://doi. org/10.4149/neo_2018_181012N764

[23] PALVE V, BAGWAN J, KRISHNAM NM, PAREEK M, CHANDOLA M et al. Detection of high-risk human papillomavirus in oral cavity squamous cell carcinoma using multiple analytes and their role in patients survival. J Glob Oncol 2018; 4: 1-33. https://doi.org/10.1200/JGO.18.00058

[24] KANSY K, THIELE O, FREIER K. The role of human papillomavirus in oral squamous cell carcinoma: Myth and reality. Oral Maxillofac Surg 2014; 18: 165-172. https://doi. org/10.1007/s10006-012-0383-0

[25] MAXWELL JH, GRANDIS JR, FERRIS RL. HPV-Associated Head and Neck Cancer: Unique Features of Epidemiology and Clinical Management. Annu Rev Med 2016; 67: 91-101. https://doi.org/10.1146/annurev-med-051914-021907

[26] ENZENHOFER E, PARZEFALL T, HAYMERLE G, SCHNEIDER S, KADLETZ L et al. Impact of Sonic Hedgehog Pathway Expression on Outcome in HPV Negative Head and Neck Carcinoma Patients after Surgery and Adjuvant Radiotherapy. PLoS ONE 2016; 11: e0167665. https://doi. org/10.1371/journal.pone.0167665

[27] BARNES L, EVESON W, REICHART P, SIDRANSKY D (Eds.). World Health Organization Clasification of Tumours. Pathology and Genetics of Head and Neck Tumours. IARC Press, Lyon 2005, p.422.

[28] EDGE SB, COMPTON CC. The American Joint Committee on Cancer: the 7th Edition of the AJCC Cancer Staging Manual and the Future of TNM. Ann Surg Oncol 2010; 17: 1471-1474. https://doi.org/10.1245/s10434-010-0985-4

[29] ZHAO H, TANG H, XIAO Q, HE M, ZHAO L et al. The Hedgehog signaling pathway is associated with poor prognosis in breast cancer patients with the CD44+/CD24-phenotype. Mol Med Rep 2016; 14: 5261-5270. https://doi. org/10.3892/mmr.2016.5856

[30] HONING J, PAVLOV K, MUL VEM, KARRENBELD A, MEIJER C et al. CD44, SHH and SOX2 as novel biomarkers in esophageal cancer patients treated with neoadjuvant chemoradiotherapy. Radiother Oncol 2015; 117: 152-158. https://doi.org/10.1016/j.radonc.2015.08.031
[31] LIM S, LIM SM, KIM MJ, PARK SY, KIM JH. Sonic hedgehog pathway as the prognostic marker in patients with extensive stage small cell lung cancer. Yonsei Med J 2019; 60: 898-904. https://doi.org/10.3349/ymj.2019.60.10.898

[32] HUAITONG X, YUANYONG F, YUEQIN T, PENG Z, WEI $S$ et al. Microvesicles releasing by oral cancer cells enhance endothelial cell angiogenesis via Shh/RhoA signaling pathway. Cancer Biol Ther 2017; 18: 783-791. https://doi.org/10. 1080/15384047.2017.1373213

[33] JIAN-HUI C, ER-TAO Z, SI-LE C, HUI W, KAI-MING W et al. CD44, sonic hedgehog, and glil expression are prognostic biomarkers in gastric cancer patients after radical resection. Gastroenterol Res Pract 2016; 2016: 1013045. https://doi. org/10.1155/2016/1013045

[34] HASHMI AA, HUSSAIN ZF, HASHMI SK, IRFAN M, KHAN EY et al. Immunohistochemical over expression of p53 in head and neck Squamous cell carcinoma: clinical and prognostic significance. BMC Res Notes 2018; 11: 433. https://doi.org/10.1186/s13104-018-3547-7

[35] PANDYA JA, NATARAJAN S. A correlation of immunohistochemical expression of TP53 and severity of inflammation with varying grades of oral squamous cell carcinoma. J Cancer Res Ther 2019; 15: 564-570. https://doi.org/10.4103/jcrt. JCRT_8_17

[36] SABITHA S, MOHAN J, MNIRMAL M, VASANTHAN P, SATHIYA JJ. Association of p53 and Bax in Oral Epithelial Dysplasia and Oral Squamous Cell Carcinoma - An Immunohistochemical study. J Adv Med Dent Scie Res 2019; 7: 67-71. https://doi.org/10.21276/jamdsr

[37] RATHISH D, WIJERATHNE BTB, KHAN R. Human Papillomavirus-Associated Oral Squamous Cell Carcinoma Among Adults Living in South-Central Asia: A Systematic Review. Indian J Otolaryngol Head Neck Surg 2020. https:// doi.org/10.1007/s12070-020-01842-9

[38] LEE LA, HUANG CG, LIAO CT, LEE LY, HSUEH C et al. Human papillomavirus-16 infection in advanced oral cavity cancer patients is related to an increased risk of distant metastases and poor survival. PLoS ONE 2012; 7: e40767. https://doi.org/10.1371/journal.pone.0040767

[39] DURAY A, DESCAMPS G, DECAESTECKER C, REMMELINK M, SIRTAINE N et al. Human papillomavirus DNA strongly corelates with a poorer prognosis in oral cavity carcinoma. Laryngoscope 2012; 122: 1558-1565. https:// doi.org/10.1002/lary.23298 